\title{
Continuity of maternal care during COVID-19 outbreak through tele-health
}

\author{
KP Jeewarathne ${ }^{1}$, GP Sudheera ${ }^{1}$, BC Mallawaarachchi ${ }^{1}$, KT Samararathna ${ }^{1}$, L Ubesekera ${ }^{2}$, LR \\ Sanjeewa $^{3}$, R Dias $^{1}$, IE Gunaratna ${ }^{1^{*}}$ \\ ${ }^{1}$ Office of the Regional Director of Health Services, Galle, Sri Lanka; ${ }^{2}$ Office of the Medical Officer of \\ Health, Bope-poddala, Galle, Sri Lanka; ${ }^{3}$ Office of the Medical Officer of Health, Elpitiya, Galle, Sri Lanka \\ "Correspondence: indeewariegunaratna@gmail.com \\ iDhttps://orcid.org/0000-0001-5949-244X
}

DOI: https://doi.org/10.4038/jccpsl.v26i5.8323

Received on 8 May 2020

Accepted on 10 June 2020

\section{Summary}

Maternal care services in Sri Lanka are recognized as one of the best services in South-East Asia. The country has a good health system for delivering all maternal and child healthcare services to grass root level. Unfortunately, these services were interrupted with the outbreak of COVID-19 in Sri Lanka. From March 2020, provision of the routine maternal and childcare services underwent alterations. This narrative report highlights the use of tele-health services to continue maternal care services when the access to services was limited due to precautions taken at field level during COVID-19 global pandemic in Sri Lanka.

\section{Public health response and its impact}

Sri Lanka has been able to maintain a low maternal mortality rate between $32-56$ per 100,000 live births over the last two decades (1). This is done through community level health managers, namely medical officers of health $(\mathrm{MOH})$ and public health midwives (PHMs). The $\mathrm{MOH}$ and his/her staff have an enormous contribution towards the improvement of pre-conceptional, antenatal and postnatal care to all women in Sri Lanka.

In Sri Lanka, maternity care is based on the shared care model delivered both by preventive care service and curative care service. Preventive care is provided by the field health staff while the curative care is provided by the health staff in secondary and tertiary care health institutions (teaching hospitals, general hospitals, base hospitals and divisional hospitals). Almost all the deliveries (99.9\%) take place at an institution with comprehensive maternity care (1).

From March onwards, the MCH services were interrupted following the outbreak of COVID-19 in Sri Lanka. Island wide curfew was imposed under the guidance of health authorities to limit public movements within the country that could worsen the condition. Consequently, access to health care by mothers expecting delivery and provision of specialized maternal care services by health staff 
were affected and curative care services were confined to essential services. With wide publicity given by the media on punishment of curfew violators, a fear was instilled among the general public including pregnant mothers for visits outside home. All these affected the care seeking behaviour of pregnant mothers.

The Family Health Bureau (FHB) and Epidemiological Unit in Sri Lanka circulated several guidelines (2-4) on continuing maternal care services at field level during the COVID-19 outbreak. Since the currently practised Reproductive Health Managed Information System (RHMIS) was not geared to capture the special services provided during this difficult time, district teams identified the requirement of integrating tele-health care to monitor field level maternal care services. Tele-health is defined as "provision of health care services, clinical information and education over a distance using telecommunication technology" (5). In Sri Lanka, mobile phones in use outnumber the total population (6). Considering this ground situation, tele-health care services were introduced to sustain uninterrupted maternal health care services to pregnant mothers of more than 32 weeks of amenorrhea during the COVID-19 outbreak. Telehealth services were limited to telephone and selected social media communications. Contact details written on mothers' pregnancy records were used for communication.

An integrated approach with patient engagement, preventive care management, curative care management and tele-health care was utilised to improve the maternal pregnancy outcomes (Figure 1). The conceptual framework was developed with the guidance of Partners Health Care Population Strategy (7). Tele-health strategy had not been practised previously in the maternal health management system due to its limitations in examining patients and detection of danger signs.



Figure 1: Integrated holistic maternal health management framework during COVID-19 outbreak 
Initially, a database was developed by all $\mathrm{MOHs}$ according to the guidelines provided by the FHB (4). All pregnant mothers $>32$ gestational weeks was given a telephone call by the area public health midwife (PHM) in order to collect information on any change in residence; availability of a delivery plan decided by the visiting obstetrician and gynaecologist (VOG) and transport arrangements in case of an obstetrics emergency. Further, they confirmed information on name, period of amenorrhea, expected date of delivery, parity, risk factors, address of mother, telephone numbers of mother and guardian and details of the VOG. During this conversation, contact details of the PHM and $\mathrm{MOH}$ were also communicated to the mother. $\mathrm{MOHs}$ were instructed to follow-up the registered mothers over the phone or by home visits. Updated databases were shared with the district office weekly by email. Hotline was available for 24 hours at the district office for MOHs to seek advice.

A total of 1956 mothers ( $>32$ gestational weeks) from all $20 \mathrm{MOH}$ areas were re-registered in the database from 18 March to 18 April 2020. This registration included mothers who have temporarily changed their residence to another PHM area within their $\mathrm{MOH}$ area or in-between $\mathrm{MOH}$ areas or in-between districts other than the mothers who were already under care of relevant PHM. All mothers registered were provided with tele-health care services through the district team. Services included,

- Advice on specific queries raised by pregnant mothers related to maternal care

- Clinical advice to mothers depending on the stage of pregnancy

- Case discussions with relevant VOGs on further care via images sent through social media communications by the area PHM and pregnant mothers

- Further guidance to field staff on continuity of care

- Coordination of transportation of pregnant mothers to curative care institutions during curfew
- Pay specific attention to pregnant mothers under quarantine

- Development of delivery plans for mothers $>36$ gestational weeks with engagement of $\mathrm{MOH}$ team, district team and VOG.

Regional supervisory public health nursing officer (RSPHNO) was held responsible for coordination at district level. Supervision of tele-health services ensured uninterrupted supply of logistics and medications, coordination with curative sector and provision of technical guidance by maternal and child health (MO-MCH) and consultant community physicians (CCP). Curative care coordination was provided by the VOG. Managerial and financial issues were addressed by the regional directors of health services. The whole team had regular meetings to monitor the progress.

Patient engagement was acquired by giving the responsibility of self-monitoring during pregnancy. Kick count charts (time taken to feel 10 foetal movements) were distributed among pregnant mothers registered with the PHM and they were advised on danger signs. All mothers were advised to inform the $\mathrm{MOH}$ even on slightest changes in monitoring parameters. In each $\mathrm{MOH}$ area, either $\mathrm{MOH}$ or PHMs were on 24 hour on-call to attend all inquiries of mothers at any time.

Out of all registered, 33\% ( $\mathrm{n}=643)$ mothers had comorbidities (Table 1). All registered mothers were benefited by the tele-health care and approximately $10 \%(\mathrm{n}=191)$ were personally attended and cared for. During this vigilance period, special attention was given to five quarantined mothers and followed-up with regular telephone calls. Further, with involvement of VOG, 16 delivery plans were developed. 
Table: 1 Distribution of co-morbidities among registered mothers of 32 weeks and above POA

\begin{tabular}{|lc|}
\hline Comorbidity & Number (Percentage) \\
\hline Anaemia & $265(13.6 \%)$ \\
\hline Gestational Diabetes mellitus & $65(3.3 \%)$ \\
\hline Long term Diabetes mellitus & $45(2.3 \%)$ \\
\hline Bronchial asthma & $44(2.3 \%)$ \\
\hline Pregnancy induced hypertension & $33(1.7 \%)$ \\
\hline Antepartum haemorrhage & $29(1.5 \%)$ \\
\hline Long term hypertension & $28(1.4 \%)$ \\
\hline Thyroid diseases & $23(1.2 \%)$ \\
\hline Heart diseases & $22(1.1 \%)$ \\
\hline Assisted reproductive techniques for subfertility & $18(0.9 \%)$ \\
\hline Influenza \& respiratory infection (diagnosed \& treated at the time of & $15(0.8 \%)$ \\
\hline registration) & $14(0.7 \%)$ \\
\hline Psychiatric illnesses & $12(0.6 \%)$ \\
\hline Uterine abnormalities & $08(0.4 \%)$ \\
\hline Epilepsy & $08(0.4 \%)$ \\
\hline Elderly mothers & $04(0.2 \%)$ \\
\hline Thalassaemia trait & $03(0.2 \%)$ \\
\hline Chicken pox & $02(0.1 \%)$ \\
\hline Urinary tract infection & $01(0.1 \%)$ \\
\hline Renal disease & $01(0.1 \%)$ \\
\hline Liver disease & $01(0.1 \%)$ \\
\hline Cellulitis & $01(0.1 \%)$ \\
\hline History of abdominal surgery (herniotomy) & $01(0.1 \%)$ \\
\hline Breast abscess & $\mathbf{6 4 3} .9 \%)$ \\
\hline Total & \\
\hline
\end{tabular}

In the routine health information system, PHMs maintain a pregnant mothers' register at village level. Yet, all the information entered in registers are not communicated to $\mathrm{MOH}$, but only a consolidated report. Therefore, a consolidated registered database for pregnant mothers $>32$ of gestational week at the MOH office level facilitated the MOHs and his/ her supervisory team to monitor the maternal care services at field level. It empowered $\mathrm{MOHs}$ in providing special attention to all pregnant mothers with or without risk factors in his/ her purview, providing comprehensive maternal care and referrals to tertiary care at individual level, and thereby prevent adverse outcomes of pregnancy especially maternal or infant deaths. It also helped them to prioritize maternal care needs during the time of having limited access to services and low health seeking behaviour of the public. This even enabled continuity of the care for mothers, who have changed their residence temporarily within the district or who 
have returned back to the district. When the curfew was lifted up, MOHs used this database to organize antenatal clinics on appointment basis to prevent overcrowding. It also helped regional staff to maintain uniformity of maternal care throughout the district during curfew. Strengths, weaknesses, opportunities and threats (SWOT) for continuity of maternal care through tele-health services are presented in Figure 2.

\section{Conclusions}

Authors believe that tele-health is a better way of continuing maternal services in situations where access to health care is limited, such as disease outbreak situations during periods of natural disasters, especially floods. This would prevent unnecessary exposure of vulnerable risk groups, such as pregnant mothers, children and elders.

\begin{tabular}{|c|c|c|c|}
\hline Strengths & Weaknesses & Opportunities & Threats \\
\hline $\begin{array}{l}\text { - Good public health } \\
\text { nekwork } \\
\text { - Free health services } \\
\text { - Committed public health } \\
\text { staff } \\
\text { - Evidence based } \\
\text { directives from the } \\
\text { national focal point }\end{array}$ & $\begin{array}{l}\text { - Difficulty in gathering } \\
\text { important clinical } \\
\text { information specially } \\
\text { danger signs } \\
\text { - Unavailability of video } \\
\text { facilities with all eligible } \\
\text { clients } \\
\text { - Decisions depend on } \\
\text { client interpretation } \\
\text { - High cost asssociated } \\
\text { with purchasing devices } \\
\text { with video facilities }\end{array}$ & $\begin{array}{l}\text { - Meet the need of } \\
\text { continuity care in } \\
\text { situations like COVID- } \\
19 \text { and in inaccessible } \\
\text { situations like } \\
\text { entrapments due to } \\
\text { disasters (ed. flood) } \\
\text { - Create a network } \\
\text { between professionals in } \\
\text { remote areas and } \\
\text { specialized institutions } \\
\text { - Platform for e-learning }\end{array}$ & $\begin{array}{l}\text { Building capacity of } \\
\text { health care workers } \\
\text { - Infrastructure } \\
\text { development to address } \\
\text { wider service coverage } \\
\text { - Public acceptance }\end{array}$ \\
\hline
\end{tabular}

Figure 2: SWOT analysis of continuity of care through tele-health

\section{Author Declaration}

Acknowledgements: All the MOHs and VOGs in Galle District

Author contributions: All authors were involved in the implementation of tele-health services, planning of the article and in literature search. KPJ, BCM and IEG drafted the manuscript and all authors were involved in editing it. IEG did the overall supervision. All authors approved the final manuscript.

\section{References}

1. Family Health Bureau. Annual Report 2017. Colombo: Family Health Bureau, Ministry of Health, 2019.

2. Ministry of Health. Interim Guidelines for Field Maternal and Child Health Care Services during the Outbreak of COVID-19 Infection: 17 March 2020.
Colombo: Ministry of Health, Sri Lanka, 2020.

3. Family Health Bureau. Maternal and child health services during curfew period in the outbreak of COVID-19 infection: 26 March 2020. Colombo: Family Health Bureau, Ministry of Health, Sri Lanka, 2020.

4. Family Health Bureau. National maternal mortality review for the year 2018. MOMCH Review, January 2020. Colombo: Family Health Bureau, Ministry of Health, Sri Lanka, 2020.

5. Mahen M, Whitten P, Allen A. E-Health, Telehealth, and Telemedicine: a Guide to Start Up and Success. San Francisco: Josse-Bass, 2001.

6. Liyanage LN. Usage of mobile phones among university students in Sri Lanka. National Conference of Applied Social Statistics, Colombo, 2015.

7. Partners Health Care. Managing half a million riskcontracted lives: partners healthcare population health strategy. Health Catalyst 2016; sl. 